\title{
Risk Factors for Type 2 Diabetes Mellitus in Children
}

\author{
Suyanne Freire de Macêdo ${ }^{1}$ \\ Márcio Flávio Moura de Araújoº \\ Niciane Pessoa Bandeira Marinho ${ }^{3}$ \\ Adman Câmara Soares Lima ${ }^{4}$ \\ Roberto Wagner Freire de Freitas ${ }^{5}$ \\ Marta Maria Coelho Damasceno ${ }^{6}$
}

This study investigates risk factors for type 2 diabetes mellitus in a population of children in public schools, Fortaleza, CE, Brazil. A total of 727 children aged 6 to 11 years old from 12 schools were evaluated between March and June 2008. A form addressing sociodemographic data, body mass index, blood pressure, capillary blood glucose and waist circumference was applied. A total of $54.1 \%$ of the children were female, $21.7 \%$ were overweight, $6.6 \%$ were obese, $27 \%$ had central obesity, $6.2 \%$ showed altered capillary glucose, and $17 \%$ high blood pressure. In relation to risk factors, $53.4 \%$ presented no risk factors; $24.3 \%$ had at least one factor and $18.8 \%$ two risk factors. Nurses can intervene in schools through educational health programs encouraging the adoption of healthy habits and identifying children at risk of type 2 diabetes mellitus.

Descriptors: Risk Factors; Children Health (Public Health); Diabetes Mellitus Type 2; Nursing.

1 RN, M.Sc. in Nursing, Assistant Professor, Universidade Federal do Piauí, Campus Floriano, PI, Brazil. Email: suyanneefreire@hotmail.com.

${ }^{2}$ RN, Doctoral Student, Universidade Federal do Ceará, CE, Brazil. Assistant Professor, Universidade Federal do Maranhão, Campus Imperatriz, MA, Brazil. Email: marciofma@yahoo.com.br.

${ }^{3}$ RN, Master's Student, Universidade Federal do Ceará, CE, Brazil. Scholarship holder FUNCAP. E-mail: nicianebpm@yahoo.com.br.

${ }^{4}$ RN, Master's Student, Universidade Federal do Ceará, CE, Brazil. Scholarship holder CAPES. E-mail: adminhacs@hotmail.com.

${ }^{5}$ RN, Master's Student, Assistant Professor, Universidade Federal do Piauí, Campus Floriano, PI, Brazil. E-mail: robertowjff@globo.com.

${ }^{6}$ RN, Ph.D. in Nursing, Retired Professor, Universidade Federal do Ceará, CE, Brazil. E-mail: martadamasceno@terra.com.br.

Corresponding Author:

Márcio Flávio Moura de Araújo

Universidade Federal do Ceará. Faculdade de Farmácia, Odontologia e En-

fermagem.

Rua Alexandre Baraúna, 1115

Bairro Rodolfo Teófilo

CEP: 60430-160 Fortaleza, CE, Brasil

E-mail: marciofma@yahoo.com.br 


\section{Fatores de risco para diabetes mellitus tipo 2 em crianças}

O estudo teve como objetivo identificar fatores de risco para diabetes mellitus tipo 2 numa população de crianças de escolas públicas de Fortaleza, CE, Brasil. Foram avaliadas 727 crianças de 6 a 11 anos de 12 escolas, nos meses de março a junho de 2008. Foi aplicado formulário abordando aspectos sociodemográficos, índice de massa corporal, pressão arterial, glicemia capilar e circunferência da cintura. Dos sujeitos, $54,1 \%$ eram do sexo feminino, $21,7 \%$ tinham excesso de peso, $27 \%$ obesidade central, 6,2\% alterações glicêmicas e 17,9\% pressão arterial elevada. Em relação aos fatores de risco, 53,4\% não apresentavam, 24,3\% tinham pelo menos um fator e $18,8 \%$, dois. A enfermagem pode atuar nas escolas por meio de ações de educação em saúde, incentivando a adoção de hábitos de vida saudáveis e na identificação de crianças com risco para diabetes mellitus tipo 2 .

Descritores: Fatores de Risco; Saúde da Criança; Diabetes Mellitus Tipo 2; Enfermagem.

\section{Factores de riesgo para diabetes mellitus tipo 2 en niños}

El estudio tuvo como objetivo identificar factores de riesgo para diabetes mellitus tipo 2 en una población de niños de escuelas públicas de Fortaleza, Brasil. Fueron evaluadas 727 niños de 6 a 11 años, de 12 escuelas, en los meses de marzo a junio de 2008. Fue aplicado un formulario abordando aspectos sociodemográficos, índice de masa corporal, presión arterial, glucemia capilar y, circunferencia de la cintura. Fue identificado que $54,1 \%$ de los sujetos eran del sexo femenino, $21,7 \%$ tenían exceso de peso, $27 \%$ obesidad central, 6,2\% alteraciones en la glucemia y 17,9\% presión arterial elevada. En relación a los factores de riesgo, $53,4 \%$ no lo presentaban, $24,3 \%$ tenían por lo menos un factor y $18,8 \%$ dos factores. La enfermería puede actuar en las escuelas por medio de acciones de educación en salud, incentivando la adopción de hábitos de vida saludables y identificando niños con riesgo para diabetes mellitus tipo 2.

Descriptores: Factores de Riesgo; Salud del Niño; Diabetes Mellitus Tipo 2; Enfermería.

\section{Introduction}

Until recently, type 2 Diabetes Mellitus (DM2) was considered a rare disease in childhood and adolescence ${ }^{(1)}$. Its increased incidence in recent years in this population, however, has presented characteristics similar to those of adults in industrialized countries. The outbreak of DM2 during childhood and adolescence is a result of a worldwide epidemic of obesity and sedentariness. Currently, more than 200 children and adolescents develop the disease every day worldwide ${ }^{(1-2)}$.

The significant increase in the number of DM2 cases, especially among children, is a concern and has been considered an emerging public health problem. Studies indicate a high incidence of the disease among children six to 11 years old(3-5).

In the United States, $8 \%$ to $45 \%$ of the new DM cases in children are type $2^{(3)}$. In European countries such as the United Kingdom, France, Austria and Netherlands, the incidence of DM1 is higher than DM2, however, the progression of this disease among the pediatric population is alarming ${ }^{(6-7)}$. In Asia, in countries such as Taiwan, there are already more than twice as many DM2 cases as there are DM1 cases. In Japan, the incidence of DM2 went from 1.7 to 2.6 cases in each 100,000 children between 1980 and $2002^{(8)}$.

There are many issues concerning DM2 in children, such as the possibility of non-diagnosed cases, individuals huge emotional overload and difficulty in establishing diagnostic and therapeutic parameters ${ }^{(3)}$, all consequences of the poor knowledge concerning the disease's physiological profile in this group. If preventive measures are not adopted, society will bear severe problems accrued from complications of the early onset of $\mathrm{DM} 2^{(3)}$. 
Because of that, the American Diabetes Association (ADA) recommends that fasting blood glucose be tested in asymptomatic obese or overweight children when two risk factors are added from among the following: family history of DM2 in first or second degree relatives, belonging to certain ethnicity (native American, African-American, Latin among others), signs of insulin resistance or conditions associated with insulin resistance (acanthosis nigricans, hypertension, dyslipidemia or polycystic ovary syndrome), or maternal history of gestational diabetes. The test should be performed in children older than 10 years of age or at the beginning of puberty, when puberty occurs at an earlier age ${ }^{(3)}$.

Interventions able to delay or avoid DM2 during childhood are possible in this context, especially those related to the adoption of a healthier lifestyle (balanced diet and regular physical exercise, among others). Given the earlier discussion, this study identifies the prevalence of modifiable risk factors for DM2 in a population of children aged six to 11 years old in Fortaleza, CE, Brazil.

This study addresses the recommendations of other studies that point to the importance of conducting investigations in schools to obtain information concerning DM2 risk factors and its determinants in children and adolescents through the verification of anthropometric measures, blood pressure (BP), glycemia, triglycerides and HDL cholesterol ${ }^{(2,4,8)}$. There is still a scarcity of studies in the literature, especially in Brazilian periodicals, which highlights the contribution of this study in relation to the prevalence of DM2 risk factors in children.

\section{Method}

This cross-sectional study addresses the prevalence of modifiable DM2 risk factors in children. It was carried out in 12 public schools in Fortaleza, CE, Brazil. According to information from the Regional Center of Educational Development (CREDE), Fortaleza, one of the main Brazilian metropolitan cities, is divided into six regions and had, in March 2007, 125,526 students registered in schools, whose ages are of interest for this investigation (six to 11 years of age); this total represents the study's population.

The following formula used in cross-sectional studies with infinite populations to compute samples was also adopted here:

$$
\mathrm{N}=\frac{\mathrm{t}^{2}{ }_{5 \%} \cdot \mathrm{P} \cdot \mathrm{Q}}{\mathrm{e}^{2}}
$$

Where $\mathrm{t}=$ Student distribution $\left(\mathrm{t}_{5 \%}=1.96\right) ; \mathrm{P}=$ $50 \% ; \mathrm{Q}=100 \%-\mathrm{P}=50 \%$; and absolute sampling error $=4 \%$. $\mathrm{P}$ and $\mathrm{Q}$ were considered because they provide the sample maximum size, in addition to the level of significance $(a=0.05)$ and absolute sampling error of $4 \%$. Therefore, the sample totaled 727 students (Table 1).

Two schools, located in different neighborhoods, especially in terms of infrastructure and services, of each of the six regions were chosen. This procedure aimed to encompass all regions in the capital in order to enable a higher level of heterogeneity in the sample in relation to socio-demographic data.

Table 1 - Sampling distribution by region. Fortaleza, $C E$, Brazil, 2008

\begin{tabular}{|c|c|c|c|c|}
\hline \multirow{2}{*}{ Regions } & \multirow{2}{*}{$\begin{array}{c}\text { Number of } \\
\text { registered } \\
\text { students }\end{array}$} & \multicolumn{2}{|c|}{ Sample by region } & \multirow{2}{*}{$\begin{array}{c}\text { Sample by } \\
\text { school }\end{array}$} \\
\hline & & $\mathbf{N}$ & $\mathbf{N}$ & \\
\hline \multirow{2}{*}{1} & \multirow{2}{*}{20,295} & \multirow{2}{*}{108} & 54 & $A$ \\
\hline & & & 54 & $B$ \\
\hline \multirow{2}{*}{ II } & \multirow{2}{*}{10,443} & \multirow{2}{*}{60} & 30 & C \\
\hline & & & 30 & $\mathrm{D}$ \\
\hline \multirow{2}{*}{ III } & \multirow{2}{*}{16,071} & \multirow{2}{*}{103} & 50 & $E$ \\
\hline & & & 53 & $\mathrm{~F}$ \\
\hline \multirow{2}{*}{ IV } & \multirow{2}{*}{8,740} & \multirow{2}{*}{52} & 26 & G \\
\hline & & & 26 & $\mathrm{H}$ \\
\hline \multirow{2}{*}{ V } & \multirow{2}{*}{35,180} & \multirow{2}{*}{204} & 95 & 1 \\
\hline & & & 109 & $J$ \\
\hline \multirow{2}{*}{ VI } & \multirow{2}{*}{34,797} & \multirow{2}{*}{200} & 105 & $J$ \\
\hline & & & 95 & $\mathrm{~K}$ \\
\hline Total & 125.526 & 727 & 727 & 12 \\
\hline
\end{tabular}

Source: City Department of Education

Children were selected according to the following inclusion criteria: being six to 11 years old, and being registered and attending school at the time of data collection. This age group was chosen because researchers have shown an increase in DM2 cases in this age range(5).

Data collection was carried out by masters students from the graduate nursing program at the Federal University of Ceará and by undergraduate research assistants between March and June 2008. Prior to data collection, the schools' principals, teachers, parents and/ or legal guardians were contacted to clarify the study's objectives, methodology and to inform them of the need for an informed consent form, which after careful reading, was signed by parents and/or legal guardians.

A form was used to record identification data and the following variables: age, gender, grade, weight, 
height, Body Mass Index (BMI), blood pressure, Waist Circumference (WC), random or fasting capillary blood glucose and time since last meal.

Individuals were weighed barefoot and with light clothing on a digital portable scale with a capacity of $150 \mathrm{~kg}$ and precise to $0.1 \mathrm{~kg}$. Height was measured with an inelastic metric tape with a $0.5 \mathrm{~cm}$ scale. In order to ensure accurate height, individuals were instructed to stand still and erect with hands flat on their thighs and head adjusted on the Frankfurt plane. BMI was computed using the formula 'weight/height ${ }^{2 \prime}$ and classified as normal, overweight and obese ${ }^{(9)}$. Children with BMI $\geq 25 \mathrm{~kg} / \mathrm{m}^{2}$ were considered overweight and those with BMI $\geq 30 \mathrm{~kg} /$ $\mathrm{m}^{2}$ were considered obese according to gender and age. Children below these values were considered normal(9).

WC was measured at the midpoint between the iliac crest and costal margin and values were established as normal or having central obesity. Children with central obesity were those whose WC were $\geq 80^{\text {th }}$ percentile(6) according to gender and age. WC corresponding to central obesity was $59.2 \mathrm{~cm}$ distributed in the $80^{\text {th }}$ percentile(10).

Even though fasting blood glucose is more reliable for diagnosing DM, the intention in this study was not to diagnose but rather screen children with glucose outside what is considered normal, which is a risk factor for developing DM2(3). Hence, capillary glucose was adopted as it has been adopted in campaigns by the Brazilian Ministry of Health carried out to identify unknown DM cases and glucose intolerance ${ }^{(11)}$.

A glucometer and respective test strips that required the smallest quantity of blood ( 0.3 micro liters) among those available on the market were used to test capillary glucose. A drop of blood was taken from the participants' fingertip (after cleansing) with a disposable needle, which after use, was discarded in a box for needle stick material and placed in the hospital waste. The results were analyzed according to the recommendation of the Brazilian Ministry of Health, which recommends that glucose testing results, at any time (without fasting), of $\leq 140 \mathrm{mg} / \mathrm{dl}$ be considered as normal values; between 141 and $149 \mathrm{mg} / \mathrm{dl}$ as dubious; $\geq 200 \mathrm{mg} / \mathrm{dl}$ probable diabetes and $\geq 270$ highly probable diabetes. When children were fasting for four or more hours, values considered normal were $\leq 100 \mathrm{mg} / \mathrm{dl}$. Results between 101 and $125 \mathrm{mg} / \mathrm{dl}$ were classified as dubious and between 126 and $199 \mathrm{mg} / \mathrm{dl}$ as altered ${ }^{(11)}$.

Blood pressure was taken by the same team member using the same equipment. The aneroid sphygmomanometers were measured by the National
Institute of Metrology, Standardization and Industrial Quality (INMETRO) before beginning the fieldwork. Measurement and analysis of BP values were based on the $V$ Brazilian Guidelines on Hypertension. Hence, this variable was stratified in normal (BP $<90^{\text {th }}$ percentile), limitrophe $\left(B P=90^{\text {th }}\right.$ percentile and $>95^{\text {th }}$ percentile), stage 1 hypertension (BP between $95^{\text {th }}$ percentile and $99^{\text {th }}$ percentile, more than $5 \mathrm{mmHg}$ ) or stage 2 (BP higher than $5 \mathrm{mmHg}$ of $99^{\text {th }}$ percentile) and white coat hypertension (BP higher than $95^{\text {th }}$ percentile in clinical settings and normal BP in environments not related to clinical practice) ${ }^{(12)}$.

The database was organized into spreadsheets in Excel and validated by triple entry. Central tendency measures were computed. For the analysis of association among categorical variables, the Chi-square test was used. A level of significance at $5 \%$ was established for all variables. The study was approved by the Research Ethics Committee at the Federal University of Ceará (protocol 18/08).

\section{Results}

The distribution of children according to gender was $54.1 \%$ female and $45.9 \%$ male. The following age groups were considered: 6 to 7,8 to 9 and 10 to 11 with a predominance of children aged 8 to 9 years old, with $40.4 \%$; the average age was 8.5 years old $(S D=1.54)$ A plurality of the children $(46.3 \%)$ were attending the $6^{\text {th }}$ and $7^{\text {th }}$ grades.

In relation to DM2 modifiable risk factors, 110 $(15.1 \%)$ children were overweight and 48 (6.6\%) were obese, thus $158(21.7 \%)$ had excess weight; the WC of 196 children (27\%) were high; the average WC was $63.3 \mathrm{~cm}$ with a standard deviation of $\pm 8.4 \mathrm{~cm}$. Fortyfour individuals $(6.2 \%)$ presented glycemic alterations: dubious result $(40-5.7 \%)$, altered results $(3-0.4 \%$ ), and probable diabetes (1-0.1\%); 130 children (17.9\%) had high systolic or diastolic BP at the time of data collection (Table 2).

In relation to $\mathrm{BMI}$, being overweight was more frequent in boys $(58-17.4 \%)$ and obesity was more frequent among girls $(27-6.9 \%)$. When all cases of excess weight were considered, boys (79-23.7\%) were more affected than girls (79-20,1\%). In relation to age, the results demonstrated that obesity was more frequent among children aged from 10 to 11 years old and being overweight among children aged from 8 to 9 years old $(27-9.2 \%)$. Central obesity was predominant among girls (108 - 27.5\%) and those from 8 to 9 years of age were the most affected (28.6\%). 
Table 2 - Distribution of children in public schools according to modifiable risk factors for DM2 - Fortaleza, CE, Brazil, 2008

\begin{tabular}{lccc}
\hline \multicolumn{1}{c}{ Modifiable risk factors } & $\mathbf{N}^{\circ}$ & $\%$ & Cl-95\% \\
\hline BMI & 569 & 78.3 & $72.2-81.2$ \\
Normal & 110 & 15.1 & $12.5-17.7$ \\
Overweight & 48 & 6.6 & $4.8-8.41$ \\
Obesity & & & \\
Waist Circumference & 531 & 73 & $69.8-76.2$ \\
$\quad$ Normal & 196 & 27 & $23.7-30.1$ \\
Central obesity & & & \\
Capillary glucose* & 40 & 5.7 & $3.94-7.3$ \\
$\quad$ Dubious & 3 & 0.4 & $0.8-3.6$ \\
Altered & 666 & 93.8 & $92.0-95.5$ \\
$\quad$ Normal & 1 & 0.1 & $0.5-1.7$ \\
Probable diabetes & & & \\
Blood pressure & 597 & 82.1 & $79.3-84.9$ \\
$\quad$ Normal & 66 & 9.1 & $6.9-11.1$ \\
Limitrophe & 64 & 8.8 & $6.7-10,8$ \\
Hypertension Stage 1 & & & \\
\hline
\end{tabular}

$*_{n}=710$ participants

BP alterations were more frequent among girls (77 - 19.6\%) and among younger individuals, that is, those between 6 and 7 years old ( $44-23.3 \%$ ). The Chi-square test did not show a statistically significant association between the variables gender $(p=0.192)$ and age $(p=0.133)$ with BP.

Table 3 - Distribution of children in public schools according to the number of modifiable risk factors for DM2. Fortaleza, CE, Brazil, 2008

\begin{tabular}{lcc}
\hline \multicolumn{1}{c}{ Number of risk factors } & $\mathbf{N}^{\circ}$ & $\%$ \\
\hline None & 388 & 53.4 \\
One factor & 177 & 24.3 \\
Two factors & 137 & 18.8 \\
Three factors & 23 & 3.2 \\
Four factors & 2 & 0.3 \\
Total & 727 & 100 \\
\hline
\end{tabular}

As was the case with the modifiable risk factors of obesity, central obesity and BP, high capillary glucose was also prevalent among girls. The 8 to 9 years old individuals $(22-7.6 \%)$ presented more glycemic alterations than the remaining individuals in the sample. However, no association was found between the variables gender $(p=0.693)$ and age $(p=0.328)$. Most of the participants $(388-53.4 \%)$ in the study did not present any of the studied risk factors for DM2 and a small percentage presented all the risks ( $2-0.3 \%$ ) (Table 3).

\section{Discussion}

The Centers for Disease Control and Prevention estimates that one in every three American children will have $\mathrm{DM}^{(2)}$. In the face of an epidemic of large proportions, ADA established criteria to classify children and adolescents at risk of developing the risk factors for DM2 mentioned earlier in this paper ${ }^{(2-3)}$. These modifiable risk factors were addressed in this study because of the interest in developing further intervention studies in the studied schools to fight these modifiable risk factors and consequently contribute to prevent or inhibit the onset of DM2 during childhood. It is worth noting that a lack of financial resources did not allow the measurement of plasma glucose levels, triglycerides and HDL cholesterol, which if outside normal parameters are modifiable risk factors for $\mathrm{DM}^{(3)}$ as well.

Studies developed in the United States and Holland stress that there is a discrepancy between the percentage of children diagnosed with DM2 based on the clinical practice of pediatricians and ADA recommendations. In the United States, for instance, agreement in DM2 diagnosis between clinical methods and that of ADA is only $21 \%(7,13)$.

This study indicates that the prevalence of excess weight, $21.7 \%$, was higher than that of other studies also carried out with children in Fortaleza, CE, Brazil whose percentages were $16.8 \%$ and $19.5 \%{ }^{(14-15)}$. When the results of this study were compared with those of other national and international studies, higher ${ }^{(1,16)}$ and lower ${ }^{(17-18)}$ percentages are also found. This divergence is not of interest since being overweight might be currently affecting a larger number of individuals earlier in life or is simply related to sampling variations and diagnosis methods.

Even though the incidence of central obesity was not substantial $(27 \%)$ in this study, it is a concern. The literature shows that this problem has increased among children and reinforces that WC in 8 years old children is a predictor of vulnerability for obesity, DM2, hypertension and metabolic syndrome in puberty and adult life. Another fact to highlight is that male children between 6 and 11 years of age are the most affected(19).

Given the strong association between overweight and DM2 development during childhood, efforts to avoid the development of obesity and potentially DM2 should be initiated early in children's lives. Promoting a healthy lifestyle during childhood is the best strategy to inhibit or reverse epidemic obesity and consequently DM2 in children(5). 
A quasi-experimental study carried out during six months of educational activities concerning health in a group of obese children served to diminish risk factors for DM2. A statistically significant reduction of the initial values was observed in the following risk factors for the studied endocrinopathy: BMI, BP, fasting glucose, total cholesterol, triglycerides, insulin resistance index, leptine and consumption of calories(20).

One of the nurses' roles given the increased prevalence of DM2 in children is to identify risk factors, especially being overweight. Accurate measurement of weight, height and BMI in schools is the first step for nurses to identify vulnerable children and prevent this endocrinopaty with the help of parents and teachers ${ }^{(21)}$. Experiences are being reported in literature, evidencing the leadership of nurses in schools in mediating health education actions between school and family and children to fight DM2 during childhood. However, for nurses to achieve success in this endeavor, improved communication skills and knowledge concerning this current problem are needed (1,21-22).

It is also important to evaluate BP after three years of age or before this age when other risk factors are present because BP is a risk factor for DM2. This study's findings revealed that $18 \%$ of the sample had high BP levels. This fact is in agreement with other studies stressing an increased incidence of hypertension among children $^{(1,14,19)}$.

Only two studies(23-24) were found that included capillary glucose testing in children, one in the United States and another in India, though both tested fasting capillary glucose. Both studies detected high capillary glucose in children, though lower than this study $(6.2 \%)$, $4.6 \%$ and $5.1 \%$ respectively.

Given the magnitude of all mentioned risk factors, one fact of concern is that $24.3 \%$ of this sample presented at least one risk factor for DM2 while $18.8 \%$ presented two factors. This is extremely worrying because sets of risk factors influence isolated risk factors and viceversa(19). Additionally, as the number of risk factors for DM2 increases in a single individual, the higher the probability of this individual to develop the disease ${ }^{(3,25)}$.

Because this is a recent public health issue, only four studies addressing risk factors for DM2 in children and adolescents were found: two American and two Brazilian. The first of the two American studies carried out with children reported that $40 \%$ of the individuals had two or more risk factors, while the second identified $22.6 \%$ of the sample as presenting at least one factor ${ }^{(1-2)}$.

The first of the two Brazilian studies developed with adolescents verified that 33\%, $7.5 \%$ and less than $1 \%$ had two, three and all factors, respectively ${ }^{(22)}$. The second identified that $33.8 \%$ of the children had at least one factor, $39.2 \%$ had two factors, $14.2 \%$ three and $2.3 \%$ had four associated factors ${ }^{(4)}$.

Therefore, programs and protocols to prevent, diagnose and classify children in relation to DM2 are urgently needed to prevent an unfavorable future epidemiological scenario.

\section{Conclusions}

Even though there is growing Brazilian scientific research addressing sets of DM2 risk factors in children, it is still incipient. The aspects surrounding the presence of these factors in children's families need to be wellcharacterized so more specific and efficient preventive and therapeutic measures may be devised.

Therefore, a strong element in this study was determining the isolated and joint prevalence of these factors in a representative sample of one of the main Brazilian cities. A limitation in this study is the lack of other important factors in the genesis of DM2 during childhood, a fact that might have underestimated the resulting prevalence. Hence, further studies in other Brazilian cities are needed to remedy this gap and better contextualize this issue in Brazil.

The profile of risk presented here points to the need for public policies to fight risk factors for DM2 in children through various actions such as programs of physical exercise and weight control in children. Nursing is already present in the school sphere to educate children in relation to sexually transmissible disease, accident prevention, and drug use, among others, and can effectively intervene in this issue and promote health education that favors the adoption of healthy life habits and also carry out nursing consultations to identify children at risk of developing DM2.

\section{References}

1. Addams MH, Lammon CAB. The presence of family history and the development of type 2 diabetes mellitus risk factors in rural children. J Sch Nurs. 2007; 23(5):259-66.
2. Urrutia-Rojas X, Menchaca J. Prevalence of risk for type 2 diabetes in school children. J Sch Health. 2006; 76(5):189-94. 
3. American Diabetes Association. Type 2 diabetes in children and adolescents. Diabetes Care. 2000; 23(3):11-9.

4. Vasconcelos HCA. Diabetes mellitus tipo 2: investigação dos fatores de risco em adolescentes de escolas particulares de Fortaleza. [Dissertação de Mestrado]. Fortaleza (CE): Departamento de Enfermagem/Universidade Federal do Ceará; 2008.

5. Corrales-Yauckoes KM, Higgins LA. Nutritional Management of the overweight child with type 2 diabetes. Pediatr Ann. 2005; 34(9):701-9.

6. Shaw J. Epidemiology of childhood type 2 diabetes and obesity. Pediatr Diabetes 2007: 8 (Suppl 9):7-15.

7. Rotteveel J, Belksma EJ, Renders CM, Hirasing RA, DelemarreVan de Waal HA. Type 2 diabetes in children in the Netherlands: the need for diagnostic protocols. Eur J Endocrinol. 2007; 157(2):175-80.

8. Urakami T, Morimoto S, Nitadori Y, Harada K, Owada M, Kitagawa T. Urine glucose screening program at schools in Japan to detect children with diabetes and its outcome-incidence and clinical characteristics of childhood type 2 diabetes in Japan. Pediatr Res. 2007; 61(2):141-5.

9. Cole TJ, Bellizzi MC, Flegal KM, Dietz WH. Establishing a standard definition for child overweight and obesity worldwide: international survey. BMJ. 2000; 320:1240.

10. Taylor RW, Jones JE, Williams SM, Goulding A. Evaluation of waist circumference, waist-to-hip, and the conicity index as screening tools for high trunk fat mass, as measured by dualenergy $\mathrm{X}$-ray absorptiometry, in children aged 3-19y. Am J Clin Nutr. 2000; 72:4905.

11. Ministério da Saúde (BR). Plano de reorganização da atenção à hipertensão arterial e ao diabetes mellitus: Manual de Hipertensão arterial e Diabetes mellitus. Brasília (DF); 2002.

12. Sociedade Brasileira de Cardiologia, Sociedade Brasileira de Hipertensão e Sociedade Brasileira de Nefrologia. Diretrizes Brasileiras de Hipertensão Arterial. 5a.ed. São Paulo (SP); 2006.

13. Rhodes ET, Finkelstein JA, Marshall R, Allen C, Gillman MW, Ludwig DS. Screening for type 2 diabetes mellitus in children and adolescents: attitudes, barriers, and practices among paediatric clinicians. Ambul Pediatr. 2006; 6(2):110-4.

14. Araújo TL, Lopes MVO, Cavalcante TF, Guedes NG, Moreira RP, Chaves ES, et al. Análise de indicadores de risco para hipertensão arterial em crianças e adolescentes. Rev Esc Enferm USP. 2008; 42(1):120-6.
15. Almeida CAN, Rubens APP, Ricco RG, Elias CP. Abdominal circumference as an indicator of clinical and laboratory parameters associated with obesity in children and adolescents: comparison between two reference tables. J Pediatr. 2007; 83(2):181-5.

16. Guedes DP, Paula IG, Guedes JERP, Stanganelli LCR. Prevalência de sobrepeso e obesidade em crianças e adolescentes: estimativas relacionadas ao sexo, à idade e à classe socioeconômica. Rev Bras Educ Fís Esporte. 2006; 20(3): 151-63.

17. Giugliano R, Melo ALP. Diagnosis of overweight and obesity in schoolchildren: utilization of the body mass index international standard. J Pediatr. 2004; 80(2):129-34.

18. Baruki SBS, Rosado LEFPL, Rosado GP, Ribeiro RCL. Associação entre estado nutricional e atividade física em escolares da Rede Municipal de Ensino em Corumbá - MS. Rev Bras Med Esporte 2006; 12(2):90-4.

19. Yoshinaga M, Sameshima K, Tanaka Y, Arata M, Wada A, Takahashi $H$. Association between the number of cardiovascular risk factors and each risk factor level in elementary school children. Circ J. 2008; 72(10):1594-7.

20. Luna-Ruiz MA, Rangel-Vásquez D, Guizar-Mendoza JM, Amador-Licona N. Modification of risk factors in the developing of diabetes mellitus type 2 in obese children. Rev Med Inst Mex Seguro Soc. 2007; 45(1):53-62.

21. Schantz S, Bobo N. School program for screening students at risk for diabetes: the School Nurse Childhood Obesity Prevention Education program. Nasnewsletter. 2009; 24(4):150-4.

22. Silva ARV, Damasceno MMC, Carvalho ZMF, Hissa MN, Almeida PC, Silva LF. Prevalencia de factores de riesgo para diabetes mellitus tipo 2 en adolescentes de Fortaleza-Brazil. Enferm Integral 2007;78:11-4.

23. Chavez MJ, Jones Z, Mobley C, Morris M, Trevino RP. Glucose Biomarkers and Anthropometric Characteristics of Low-Income Mexican-American Children [abstract]. Abstracts de 44th Annual Conference on Cardiovascular Disease Epidemiology and Prevention; 2004 March 3-6; San Francisco (Estados Unidos). [acesso 13 out 2008]. Disponível em: http://professional. diabetes.org/Abstracts_Display.aspx?TYP $=1 \& C I D=45861$

24. Chada RR, Chitturi S, Sethi BK, Naidu SK, Rao VV, Waghray K. Prevalence of Impaired Fasting Glucose and Type 2 Diabetes Among South Indian Urban School Children [abstract]. Abstract de American Diabetes Association 68th Scientific Sessions; 2008 June 6-10; San Francisco (Estados Unidos). [acesso 13 out 2008]. Disponível em: http://www.mindcull.com/searchresults_ full.php?doc=d08ad2b580667f6ae9d7093bcbbeeccf

25. Ortiz MCA, Zanetti ML. Levantamento dos fatores de risco para diabetes mellitus tipo 2 em uma instituição de ensino superior. Rev. Latino-Am. Enfermagem. 2001; 9(3):58-63.

Received: Nov. 29th 2009

Accepted: Jul. $16^{\text {th }} 2010$ 